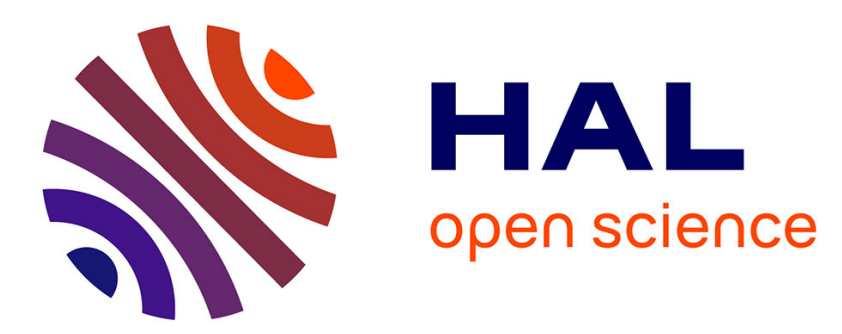

\title{
Collaborative Decision-Making Model of Green Supply Chain: Cloud-Based Metaheuristics
}

Ehsan Yadegari, Xavier Delorme

\section{To cite this version:}

Ehsan Yadegari, Xavier Delorme. Collaborative Decision-Making Model of Green Supply Chain: Cloud-Based Metaheuristics. 22nd Working Conference on Virtual Enterprises (PRO-VE 2021), Nov 2021, Saint-Etienne, France. pp.710-718, 10.1007/978-3-030-85969-5_67 . emse-03350052

\section{HAL Id: emse-03350052 https://hal-emse.ccsd.cnrs.fr/emse-03350052}

Submitted on 25 Nov 2021

HAL is a multi-disciplinary open access archive for the deposit and dissemination of scientific research documents, whether they are published or not. The documents may come from teaching and research institutions in France or abroad, or from public or private research centers.
L'archive ouverte pluridisciplinaire $\mathbf{H A L}$, est destinée au dépôt et à la diffusion de documents scientifiques de niveau recherche, publiés ou non, émanant des établissements d'enseignement et de recherche français ou étrangers, des laboratoires publics ou privés. 
Yadegari E., Delorme X. (2021) Collaborative Decision-Making Model of Green Supply Chain: Cloud-Based Metaheuristics. In: Camarinha-Matos L.M., Boucher X., Afsarmanesh H. (eds) Smart and Sustainable Collaborative Networks 4.0. PRO-VE 2021. IFIP Advances in Information and Communication Technology, vol 629. Springer, Cham. https://doi.org/10.1007/978-3-030-85969-5_67

\title{
Collaborative Decision-Making Model of Green Supply Chain: Cloud-Based Metaheuristics
}

\author{
Ehsan Yadegari ${ }^{1[0000-0001-8877-9853]}$ and Xavier Delorme $e^{1[0000-0002-9465-1255]}$ \\ ${ }^{1}$ Mines Saint-Etienne, Univ Clermont Auvergne, CNRS, UMR 6158 LIMOS, Institut Henri \\ Fayol, F -42023 Saint-Etienne France. \\ ehsan.yadegari@emse.fr
}

\begin{abstract}
The inter-organizational collaborative supply chain (SC) network involves the collaboration of various firms and decision-makers to increase the whole efficiency of an SC network. There is often a conflict between operations and environmental managers in how to design a supply network to simultaneously reduce greenhouse gas emissions and logistics costs. In this paper, a twodimensional collaborative decision-making (CDM) model for a SC network is developed. The proposed network is assumed to deliver the final product to customers in the forward flow from suppliers through manufacturers and distribution centers (DCs). Simultaneously, collecting recycled products from customers and entering them into a recovery cycle is examined. Mathematical modeling of this problem is going to minimize both the total costs and the environmental negative effects. To effectively manage the conflict, Pareto solutions for the bi-objective model are provided. Moreover, a cloud-based simulated annealing algorithm (CSA) has been applied for the first time in this area. We have compared its performance with the genetic algorithm (GA) and the simulated annealing (SA) algorithm of the literature.
\end{abstract}

Keywords: Collaborative Supply Chain, Green; Cloud-based Simulated Annealing

\section{$1 \quad$ Introduction}

Recently, supply-chain network CDM has attracted operations research analysts' attention. A large number of papers have concentrated on problems relevant to this area, like centralized CDM and decentralized CDM.

References on centralized CDM mainly apply operations research tools such as network analysis, dynamic programming, and heuristics to identify the optimal or nearoptimal decision items. On the other hand, research on decentralized decision-making has been done to enhance the applicability of CDM solutions[1]. As, this study is in the category of centralized CDM, in this part, we concentrate more on the SC modeling and solution approaches of centralized collaborative SCs, especially Supply chain network design (SCND) problems. Recently, there are some publications in centralized collaborative SCND in which all units of the SC share information regarding demand and rate of return [2,3]. However, these papers only focused on SC costs and there is no focus on environmental costs. 
SCND involves strategic decisions that refer to supply chain configuration and as an infrastructure issue in SC management, it has long-lasting effects on other tactical and operational decisions of a company. In general, the network design project faces identifying locations and capacities needed for new facilities and planning to purchase, production, distribution, and maintenance of products.

Pishvaee et al. [4] have classified the integration of SCND into two categories: (1) vertical and (2) horizontal integration. Vertical integration is defined as the integrated decisions at strategic (long-term), tactical (mid-term), and operational (short-term) levels in SCND. Designing the SC network is in the class of a strategic decision that typically involves determining the location of facilities, their capacities, the number of categories in the chain, and how the facilities are related. Therefore, it should be noted that integrating lower-level decisions in network design must be accompanied by maintaining strategic-level decisions.

In this regard, according to the literature review [5, 6], the 2013 to 2021 studies in the SCND area have been investigated in terms of decision problems, and solution approaches. Numerous approaches have been developed regarding the methodologies for representing SCND solutions. The most important ones are Matrix-based, Prufer Numbers, Priority based, and the spanning tree concept. In table (1) the research background has been classified.

Table 1. Literature review on SCND based on decision types and solution methodology.

\begin{tabular}{|c|c|c|c|c|c|}
\hline \multirow[b]{2}{*}{ Networks } & \multirow{2}{*}{$\begin{array}{l}\text { Solution } \\
\text { Representation }\end{array}$} & \multirow{2}{*}{$\begin{array}{l}\text { Solution } \\
\text { Methodology }\end{array}$} & \multicolumn{3}{|c|}{ Decision problem } \\
\hline & & & Location & $\begin{array}{c}\text { Distribution } \\
\text { organization }\end{array}$ & $\begin{array}{l}\text { Green } \\
\text { Effect }\end{array}$ \\
\hline \multicolumn{6}{|l|}{ Forward networks } \\
\hline Jayaraman, Gupta [7] & Matrix-based & SA & $\checkmark$ & & \\
\hline Pishvaee and Razmi [4] & --- & Interactive Fuzzy & $\checkmark$ & $\checkmark$ & $\checkmark$ \\
\hline Syarif and Yun [8] & Matrix-based & GA & $\checkmark$ & $\checkmark$ & \\
\hline Elhedhli and Merrick [9] & -- & $\begin{array}{l}\text { Lagrangian } \\
\text { Relaxation }\end{array}$ & $\checkmark$ & $\checkmark$ & $\checkmark$ \\
\hline \multicolumn{6}{|l|}{ Reverse networks } \\
\hline Krikke, van Harten [10] & --- & Exact Solution & $\checkmark$ & $\checkmark$ & \\
\hline Min and Ko [11] & Matrix-based & GA & $\checkmark$ & & \\
\hline Aras and Crowther [12] & Matrix-based & Tabu Search & $\checkmark$ & & $\checkmark$ \\
\hline Nezamoddini [13] & Priority-Based & GA & $\checkmark$ & & \\
\hline \multicolumn{6}{|l|}{ Closed-loop networks } \\
\hline Wang and Hsu [14] & Spanning Tree & GA & $\checkmark$ & $\checkmark$ & \\
\hline Devika, Jafarian [15] & Priority-Based & Hybrid & $\checkmark$ & $\checkmark$ & $\checkmark$ \\
\hline Yadegari, Zandieh [16] & Spanning Tree & Hybrid & $\checkmark$ & $\checkmark$ & \\
\hline Kaya and Urek [17] & Priority-Based & Hybrid Heuristics & $\checkmark$ & $\checkmark$ & \\
\hline Yi, Huang [18] & Other & Genetic Algorithm & $\checkmark$ & $\checkmark$ & \\
\hline This Paper & Spanning Tree & CSA & $\checkmark$ & $\checkmark$ & $\checkmark$ \\
\hline
\end{tabular}

The remainder of the manuscript is dedicated to the mathematical model of the SCND problem with focusing on the conflict between environmental and operational managers. In section 4, the CSA algorithm is applied to the SCND problem for the first time 
in the literature. Section 5 provides a sample Pareto solution and how sensitivity analysis is applied to smooth the conflict between decision-makers and finally the conclusion is provided in section 6 .

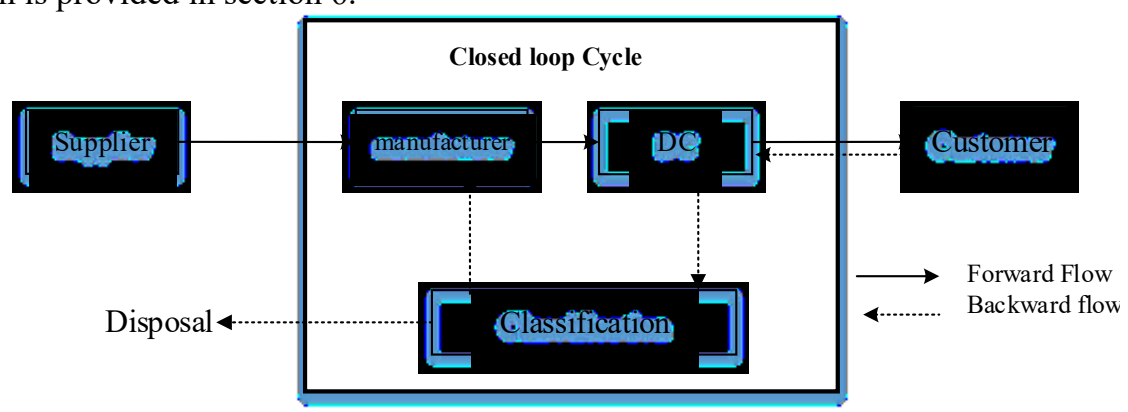

Fig. 1. The overall formation of SC network

\section{$2 \quad$ Mathematical Model}

The proposed CDM model is an extension of the model provided in $[14,16]$ in which their model only considered one objective function related to the total cost of shpping and developing facilities. However, the provided model in this paper simultaneously considers the cost and environmental effect of the SC. To be concise, in section 2 we only mention the extension of the model so for a better understanding of the model please refer to the mentioned literature.

The following describes the sets, parameters, and variables of the SCND model based on the network configuration provided in figure 1 .

Sets:

I $\quad$ Fixed locations of suppliers

$$
\begin{array}{llll}
I & \text { Fixed locations of suppliers } & I=\{1,2, \ldots,|I|\} & i \in I \\
J & \text { Potential locations for developing manufactories } & J=\{1,2, \ldots,|J|\} & j \in J \\
K & \text { Potential locations for developing DCs } & K=\{1,2, \ldots,|K|\} & k \in K \\
L & \text { Fixed locations of customers } & L=\{1,2, \ldots,|L|\} & l \in L
\end{array}
$$$$
K \quad \text { Potential locations for developing DCs } \quad K=\{1,2, \ldots,|K|\} \quad k \in K
$$$$
M \quad \text { Potential locations for developing dismantlers } \quad M=\{1,2, \ldots,|M|\} \quad m \in M
$$

\section{Parameters:}

$E R J_{j} \quad$ Emission rate of developing a plant in potential location $j$

$E R K_{k} \quad$ Emission rate of developing a DC in potential location $k$

$E R M_{m} \quad$ Emission rate of developing a dismantler in potential location $m$

$E I J_{i j} \quad$ Emission rate of shipping from supplier $i$ to manufactory $\mathrm{j}$

$E J K_{j k} \quad$ Emission rate of shipping from plant $j$ to DC $k$

$E K L_{k l} \quad$ Emission rate of shipping from DC $k$ to customer zone $l$

$E K M_{k m} \quad$ Emission rate of shipping from DC $k$ to dismantlers $m$

$E M J_{m j} \quad$ Emission rate of shipping from dismantlers $m$ to manufactory $j$

\section{Decision Variables:}

$X_{i j} \quad$ Quantity produced at plant $\mathrm{j}$ by raw materials of supplier $i$ 


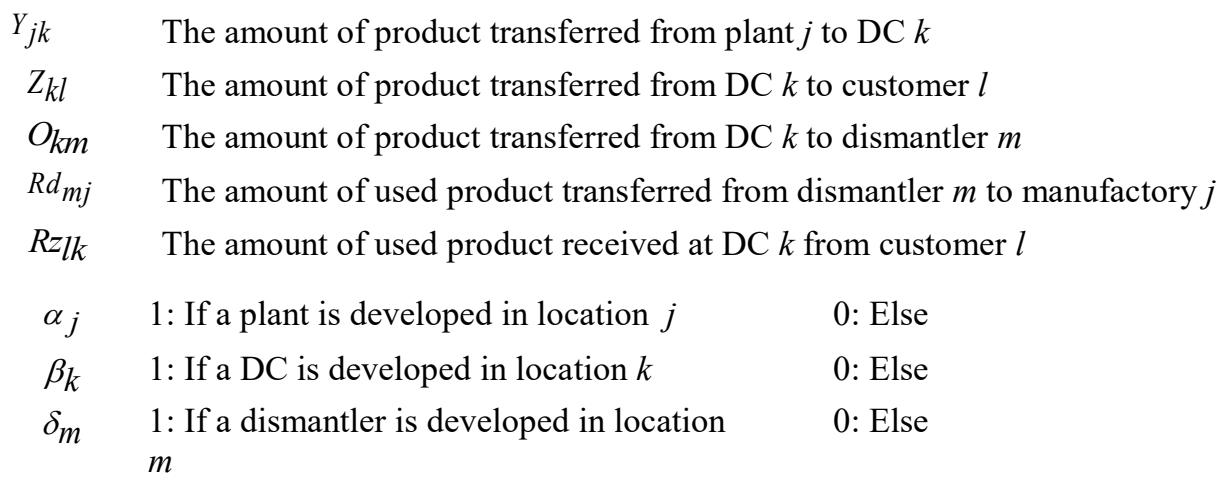

According to the aforementioned symbols, the bi-objective mixed-integer linear programming is proposed for the green forward / reverse SCND to minimize costs and emission rate as follows (the first objective and the constraints can be found in [14, 16]):

Emission Rate

$$
\begin{aligned}
& \sum_{j} E R J_{j} \alpha_{j}+\sum_{k} E R K_{k} \beta_{k}+\sum_{m} E R M_{m} \delta_{m}+ \\
& \sum_{i} \sum_{j} E I J_{i j} \cdot x_{i j}+\sum_{j} \sum_{k} E J K_{j k} \cdot y_{j k}+\sum_{k} \sum_{i} E K L \cdot z \\
& k l \\
& \sum_{k} \sum_{m} E K M . o_{k m}+\sum_{m} \sum_{j} E M J \cdot R d_{m j}+\sum_{l k} \sum_{k} E L K_{l k} \cdot R z l k
\end{aligned}
$$

The objective function in verbal form:

- $\quad$ Minimum cost $=$ Fixed costs of reopening + Shipping costs

- $\quad$ Minimum Emission = Emission of constructing facilities (plants, DCs, and dismantlers) + Shipping emission

The first objective function of the CDM model is to minimize costs, which includes transportation costs within the network and the fixed costs of developing units in potential locations. The second objective function (1) aims to minimize the total emissions of developing units in potential locations and the emission from the transferring of products between different layers of the SC network. The constraints generally contain four types and a verbal description of them is provided as below:

- Facility capacity: the incoming and outgoing products to each facility should be equal to or less than the related capacity.

- Flow constraints: the amount of input to each center must be equal to the amount of output from the same center.

- Demand Constraint: All the demands should be satisfied.

- Logical constraints: non-negativity and binary nature of variables should be considered.

\section{Solution Approach}

Since the closed-loop SCND problem is NP-hard, applying efficient metaheuristics is highly beneficial especially when dealing with large instances. One of the important 
sections of metaheuristics is a solution encoding method. The spanning-tree encoding method, as an efficient solution encoding method, is generally used in problems where there is no loop. However, the closed-loop SCND problem contains a loop. By dividing it into smaller parts, where there is no loop, this can be resolved. For more information about encoding, decoding, and the repair mechanism of this approach please refer to [14]. The advantage of the spanning tree method comparing to other methods in the literature is its minimum usage of alleles in a chromosome while the disadvantage of this method is the difficulty of coding and decoding since it needs many types of repairing mechanisms.

Following the research activities regarding the development of SA, Lu, Yuan, and Zhang [19] presented a cloud theory-based approach that enabled better neighborhood search and obtaining better solutions. The cloud modeling is a kind of modeling that incorporates qualitative concepts and quantitative representation that utilizes natural language for this purpose.

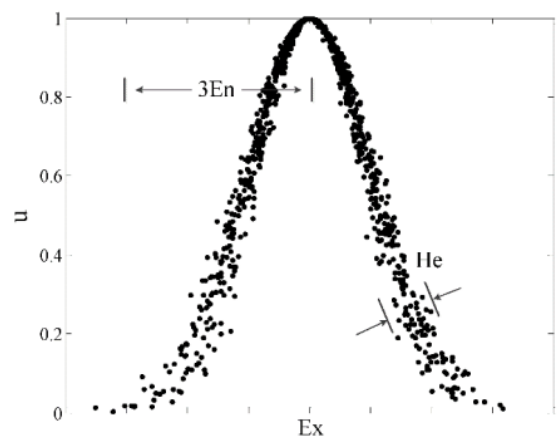

Fig. 2. Three digital characteristics of a normal cloud. [19]

To obtain almost persistent annealing temperature, the CSA gets advantages of the Metropolis rule and applies the $\mathrm{Y}$ status normal cloud generator. By incorporating the cloud theory, the random conversion of annealing temperature can increase the diversity of the searched space and avoid being trapped by a local minimum more efficiently than an original SA algorithm. Furthermore, the permanent tendency of annealing temperature can faster detect better answers and thus improve the efficiency of the SA algorithm. In fact, by revising the temperature change pattern in the SA algorithm, we are likely to see more speed and accuracy in solving the NP-hard problems. In the following section, we will discuss the results of applying CSA on SCND.

\section{Computational Results}

For the integrated problem of forward/ reverse SCND, 14 test problem samples are used from small to large sizes based on a steel company in Iran. Some other data are generated based on papers in the literature: Wang and Hsu [14] and Yadegari et al.[16, 20].

In this part, the CSA's performance is compared to the performance of two of the algorithms in the literature that used the spanning tree representation method to solve the NP-hard problem. The first algorithm is GA developed in [14] and the second is the 
SA developed in [16]. The three mentioned meta-heuristics are compared for efficiency and effectiveness. The results obtained from the implementation of the algorithms for the given problems are pertaining of the best objective function value in the closedloop SCND.

For coding the algorithms MATLAB7.11.0(R2014b) and for comparing the algorithms, Tukey Test and Two-Way ANOVA are applied. The results of implementation of algorithms are analyzed from the following two points of view: 1 . The best amount of the objective function and 2. The CPU time.

In figure 3 (right side), we examined the output obtained from the variance analysis and $95 \%$ confidence interval for the best value of the objective function. According to these two analyses performed on this criterion, the CSA is superior to the GA algorithm, but there is no significant difference between the SA algorithm and GA.
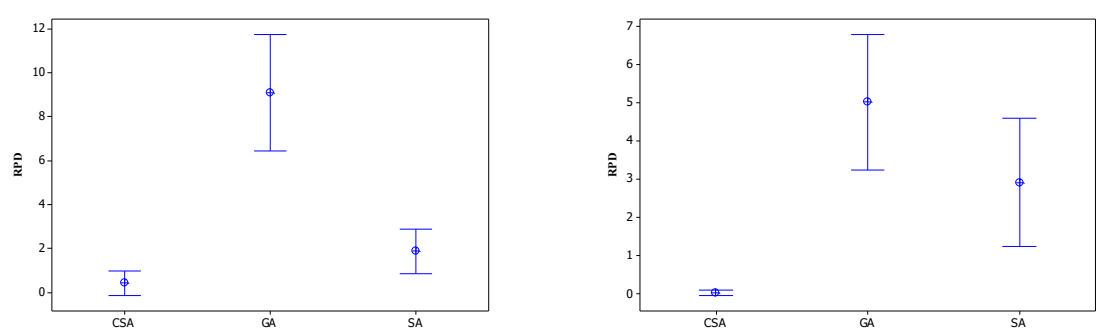

Fig. 3 the objective functions (right) and the running time (left)

The results of Tukey's test are illustrated in figure 3 (left part) for the algorithms' running time and it shows that the CSA and SA are significantly different from GA in terms of CPU time consumption. It should note that the stopping criteria for each algorithm meet when they show no progress after 20 iterations.

\section{$5 \quad$ Managerial Findings of Collaborative Decision Making}

In figure 4, the trade-off between two objective functions is shown in which the weight of objective function one (total cost) is $w$ : $\{0.99,0.9,0.8,0.7,0.6,0.5,0.4,0.3,0.2,0.1$, and 0.01$\}$. On the other hand, the weight of the second objective (total environmental negative effect) is $1-w$.

The curve shows us the potentially non-dominated solutions obtained from CSA. As there are usually many conflicts between environmental and operational managers of a collaborative SC contributors, Pareto frontier can help these decision-makers to first avoid non-optimal solutions to their problem as Pareto frontier efficiently eliminate dominated solutions and second, by sensitivity analysis on the weight of each objective, they can find out the cost of environmental decisions on the total SC. For example, in figure 4 , considering $w=0.7$ as a point with more emphasis on environmental objective than $w=0.8$, putting more weight on environmental objective the total cost of the network will increase and this cost growth would be the environmental cost of our deci- 
sion. Whereas, sometimes, the horizontal collaborative network can bear a little additional cost to gain more competitive advantage through considering environmental issues.

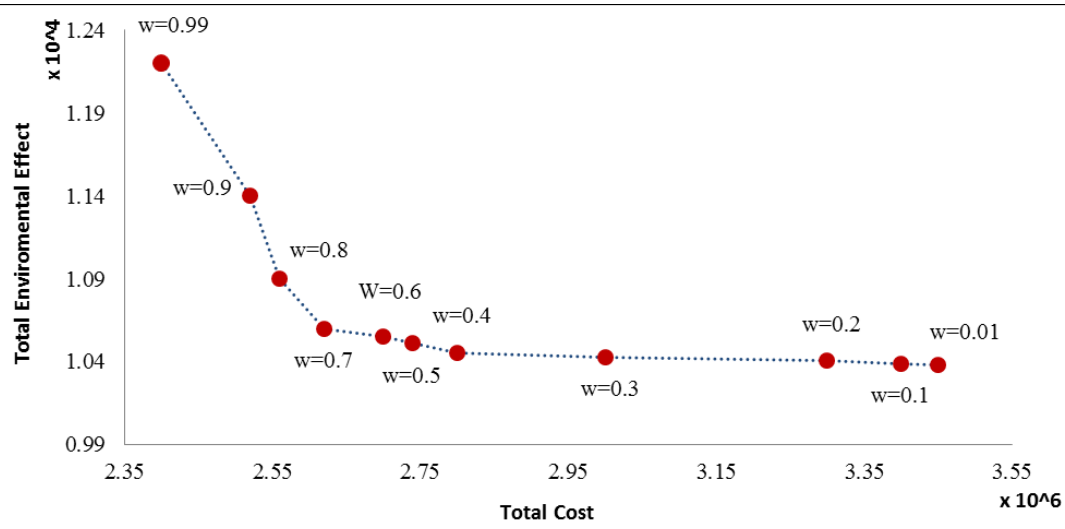

Fig. 4 Trade-off between Environmental and Economics goals

\section{Conclusion}

Recently, horizontal and centralized collaborations have become a very productive strategy in SCs, particularly from a green point of view. The collaborative closed-loop SCND model discussed in this paper was a multi-echelon network, which included suppliers, plants, distribution/collection, dismantler centers, and customer zones. The aim was to minimize the total costs and environmentally negative effects with the collaboration of all parts of the network and enable operations and environmental managers to make a tradeoff analysis between SC costs and the amount of $\mathrm{CO} 2$ emission. Considering a variety of characteristics and real-world conditions, a new algorithm in this field was presented using the complex spanning tree representation method to improve the running time and provide more accurate solutions to problems of different sizes. These algorithms were then compared with each other regarding the solutions' quality and the CPU time.

The literature on SCND models considering green principles and the profit is not in its maturity. One of the limitations of this study is that it is usually complicated to determine the exact amount of return product so that one of the future expansion of the paper can be considered as independent possibilistic variables. Moreover, researchers can extend horizontal collaboration with other external sections. Besides, assessment criteria and modeling methodologies should be enhanced for more effective decisionmaking on green aspects.

\section{References}

1. Long, Q., A flow-based three-dimensional collaborative decision-making model for supplychain networks. Knowledge-Based Systems, 2016. 97: p. 101-110. 
694 E. Yadegari and X. Delorme

2. Acevedo-Chedid, J., et al., Production System in a Collaborative Supply Chain Considering Deterioration. International Journal of Applied and Computational Mathematics, 2021. 7(3): p. 1-46.

3. Walters, M., Quantifying the Benefits of a Collaborative Supply Chain Network using a Discrete-Time Vehicle Routing Model. 2021.

4. Pishvaee, M.S. and J. Razmi, Environmental supply chain network design using multiobjective fuzzy mathematical programming. Applied Mathematical Modelling, 2012. 36(8): p. 3433-3446.

5. Van Engeland, J., et al., Literature review: Strategic network optimization models in waste reverse supply chains. Omega, 2020. 91: p. 102012.

6. Aloui, A., et al., Systematic literature review on collaborative sustainable transportation: overview, analysis and perspectives. Transportation Research Interdisciplinary Perspectives, 2021. 9: p. 100291.

7. Jayaraman, V., R. Gupta, and H. Pirkul, Selecting hierarchical facilities in a serviceoperations environment. European J. of Operational Research, 2003. 147(3): p. 613-628.

8. Syarif, A., Y. Yun, and M. Gen, Study on multi-stage logistic chain network: a spanning tree-based genetic algorithm approach. Computers \& Industrial Engineering, 2002. 43(1): p. 299-314.

9. Elhedhli, S. and R. Merrick, Green supply chain network design to reduce carbon emissions. Transportation Research Part D: Transport and Environment, 2012. 17(5): p. 370-379.

10. Krikke, H., A. van Harten, and P. Schuur, Business case Oce: reverse logistic network redesign for copiers. OR-Spektrum, 1999. 21(3): p. 381-409.

11. Min, H. and H.-J. Ko, The dynamic design of a reverse logistics network from the perspective of third-party logistics service providers. International Journal of Production Economics, 2008. 113(1): p. 176-192.

12. Aras, G. and D. Crowther, Governance and sustainability: An investigation into the relationship between corporate governance and corporate sustainability. Management Decision, 2008. 46(3): p. 433-448.

13. Nezamoddini, N., A. Gholami, and F. Aqlan, A risk-based optimization framework for integrated supply chains using genetic algorithm and artificial neural networks. International Journal of Production Economics, 2020. 225: p. 107569.

14. Wang, H.-F. and H.-W. Hsu, A closed-loop logistic model with a spanning-tree based genetic algorithm. Computers \& operations research, 2010. 37(2): p. 376-389.

15. Devika, K., A. Jafarian, and V. Nourbakhsh, Designing a sustainable closed-loop supply chain network based on triple bottom line approach: A comparison of metaheuristics hybridization techniques. European J. of Operational Research, 2014. 235(3): p. 594-615.

16. Yadegari, E., M. Zandieh, and H. Najmi, A hybrid spanning tree-based genetic/simulated annealing algorithm for a closed-loop logistics network design problem. International Journal of Applied Decision Sciences, 2015. 8(4): p. 400-426.

17. Kaya, O. and B. Urek, A mixed integer nonlinear programming model and heuristic solutions for location, inventory and pricing decisions in a closed loop supply chain. Computers \& Operations Research, 2016. 65: p. 93-103.

18. Yi, P., et al., A retailer oriented closed-loop supply chain network design for end of life construction machinery remanufacturing. J. of Cleaner Production, 2016. 124: p. 191-203.

19. Lv, P., L. Yuan, and J. Zhang, Cloud theory-based simulated annealing algorithm and application. Engineering Applications of Artificial Intelligence, 2009. 22(4-5): p. 742-749.

20. Yadegari, E., A. Alem-Tabriz, and M. Zandieh, A memetic algorithm with a novel neighborhood search and modified solution representation for closed-loop supply chain network design. Computers \& Industrial Engineering, 2019. 128: p. 418-436. 